\title{
Diagnostic and Statistical Manual of Mental Disorders, 3rd Edition
}

National Cancer Institute

\section{Source}

National Cancer Institute. Diagnostic and Statistical Manual of Mental Disorders, 3rd

Edition. NCl Thesaurus. Code C86967.

Published by the American Psychiatric Association, the DSM is a listing of currently recognized mental health disorders and their diagnostic criteria, for children and adults. It includes statistical information on etiology, incidence, prevalence, age of onset and prognosis. The 3rd edition was published in 1980. As new information becomes available subsequent editions are published. 